Nancy Consuelo Quiroga Buitrago*

\title{
Construcciones simbólicas: forma y contenido en el escapulario de la Virgen del Carmen ${ }^{1}$
}

\author{
Symbolic constructions: form and content in the scapular \\ of the Virgin of Carmen
}

Cómo citar:

Quiroga, N. (2017). Construcciones simbólicas: forma y contenido en el escapulario de la virgen del Carmen. Designia, 5(1), 85-113.

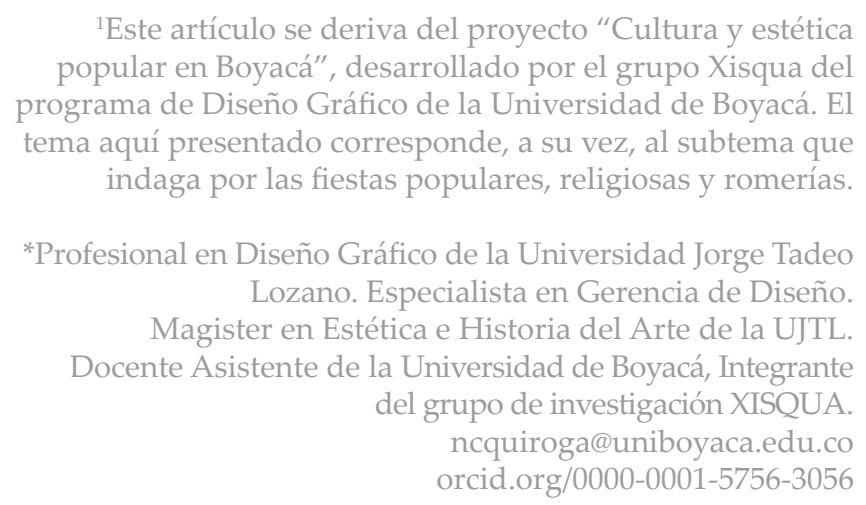

Palabras clave:

Escapulario, imaginario religioso, forma, simbolismo, mensaje.

Key words:

Scapular, religious imaginary,

form, symbolism, message.

Recibido: 11/11/2016

Aceptado: 05/07/2017

Resumen:

El presente artículo de reflexión derivado de investigación presenta los resultados del proyecto "Cultura y estética popular en Boyacá", en lo correspondiente al estudio de caso de la ciudad de Duitama. El objeto de estudio fue el escapulario, elemento de marcada importancia en la iconografía de la Virgen del Carmen. Los objetivos fueron establecer los condicionantes que lo hacen un proveedor de construcciones simbólicas, y cómo estas constituyen un conjunto de prácticas culturales populares. En primer lugar, se determinan los aspectos históricos y culturales más importantes de la Virgen del Carmen, para abordar posteriormente el 
análisis estético del escapulario como objeto e imagen y su incidencia en espacios populares. Se realizó un estudio de corte cualitativo que exploró la noción de amuleto desde el imaginario religioso y las prácticas simbólicas proveedoras de significado, en especial para los transportadores. En segundo lugar, se examina el elemento formalmente desde conceptos básicos de diseño, tales como dirección, fuerza y tensión visual, los cuales resultan relevantes en la lectura e interpretación de sus mensajes y códigos de contenidos simbólicos. Por último, tras evaluar los datos resultantes de la aplicación de una encuesta y exponer sus primeros resultados, se pone en evidencia el valor clave del escapulario en la configuración y decoración de los vehículos de los transportadores, como también su incidencia en las construcciones simbólicas propias de las prácticas populares.

\section{Abstract:}

This reflection article discusses the results of the project Culture and popular aesthetics in Boyacá, concerning the case study of Duitama, a Colombian city. The focus was on the scapular, an important element in the Virgin of Carmen's iconography. The research objectives were identifying what factors enable this element to generate symbolic constructions, and how such constructions shape significant popular cultural practices. First, a historical and cultural background on the Virgin of Carmen is provided, which is followed by the aesthetic analysis of the scapular as both object and image, along with its impact in popular contexts. A qualitative study was carried out, analyzing the idea of amulet from the religious imaginary and the meaningful symbolic practices it fosters, especially among drivers. Second, the object is examined under concepts of design, such as direction, force and visual tension, which are key in reading and interpreting its messages and symbolic contents. Finally, the first results from a survey are examined, evidencing the value of the scapular in the decoration of the driver's vehicles as well as in constructing symbolisms framed in popular practices.

\section{INTRODUCCIÓN}

En la sociedad actual y gracias a la interculturalidad, se hace valioso el estudio sobre el intercambio y el enriquecimiento de la cultura popular de nuestros pueblos. Si bien la interacción es una característica de estos procesos, las manifestaciones visuales resultantes de los imaginarios religiosos de creencia se convierten en un factor clave en el reconocimiento de distintos valores de la humanidad. 
Este artículo aborda la importancia de la festividad religiosa en la cultura popular y las construcciones simbólicas presentes en la configuración de la fiesta y la romería, específicamente las generadas en torno a la Virgen del Carmen en Duitama (Boyacá), donde las expresiones se extienden a objetos y espacios que complementan la carga ceremonial y simbólica. Inicialmente se realiza una contextualización histórica y cultural acerca de las características de la celebración. Este estudio pre-iconográfico detalla los elementos de tal advocación mariana, con el fin de analizar el escapulario como objeto configurado desde la forma y el diseño, proveedor de un mensaje específico. A continuación, se identifica la población sobre la que esta festividad ejerce mayor influencia y las prácticas sociales observables en la conmemoración. Posteriormente, mediante el análisis de las encuestas se determina la percepción de los transportadores. En las conclusiones se destaca la importancia de reconocer que en la cultura popular se gestan formas de pensamiento y experiencias cuyo estudio ayuda a descifrar esas significaciones.

Duitama, uno de los municipios más importantes del departamento de Boyacá, se sitúa en el centro-oriente de Colombia. Considerado el principal puerto transportador terrestre del corredor del oriente del país, perteneció a un caserío muisca, pero debido al mestizaje la gran mayoría de prácticas y costumbres indígenas desaparecieron, en tanto otras entraron en hibridación y la población de las comunidades precolombinas disminuyó ampliamente. Los primeros misioneros educadores que arribaron al pueblo pertenecían a la orden de Santo Domingo y consagraron el lugar como centro doctrinal, establecido después como parroquia.

El escapulario, objeto estudiado en este trabajo, ocupa un rol principal en la veneración de la Virgen del Carmen, a la cual se ha consagrado históricamente el gremio del transporte, una actividad central en Duitama. Además de haberse convertido en un identificador de la creencia y devoción por la advocación, guarda relación con las prácticas de sus fieles, pues forma parte del culto activo. Sus antecedentes históricos se refieren no solo a la imagen sagrada en sí y sus elementos, sino también a sus prácticas devocionales, al haber convivido en disímiles contextos sociales y económicos a través del tiempo. Ha sido un proveedor de elementos visuales que configuran mensajes insertos en el contexto y ha generado resignificaciones de la propia imagen. 


\section{ASPECTOS HISTÓRICOS \\ Y CULTURALES DE LA VIRGEN DEL CARMEN Y EL ESCAPULARIO}

Sobre la religiosidad popular en Colombia se conocen muchas prácticas y devociones. Una de las más sobresalientes es la relacionada con la Virgen del Carmen, que ha ganado devotos a lo largo de la historia. La imagen ha sido fuente de protección para sus seguidores, que en el contexto regional son los conductores.

La Virgen toma su nombre del Monte Carmelo, situado en la costa mediterránea de Israel, considerado un símbolo de fertilidad y belleza donde numerosos profetas se refugiaban en las cuevas existentes para rendir culto a Dios, entrar en oración, penitencia y abstinencia. Cuando un grupo de devotos se instaló en el valle próximo y escogió a la Virgen María como patrona, edificó la primera iglesia dedicada a venerar a Santa María del Monte Carmelo. Estos devotos vivieron en comunidad bajo la oración y la pobreza y fueron la cuna de la Orden de los Carmelitas, de cuya devoción a la Virgen surgió la advocación de Nuestra Señora del Carmen.

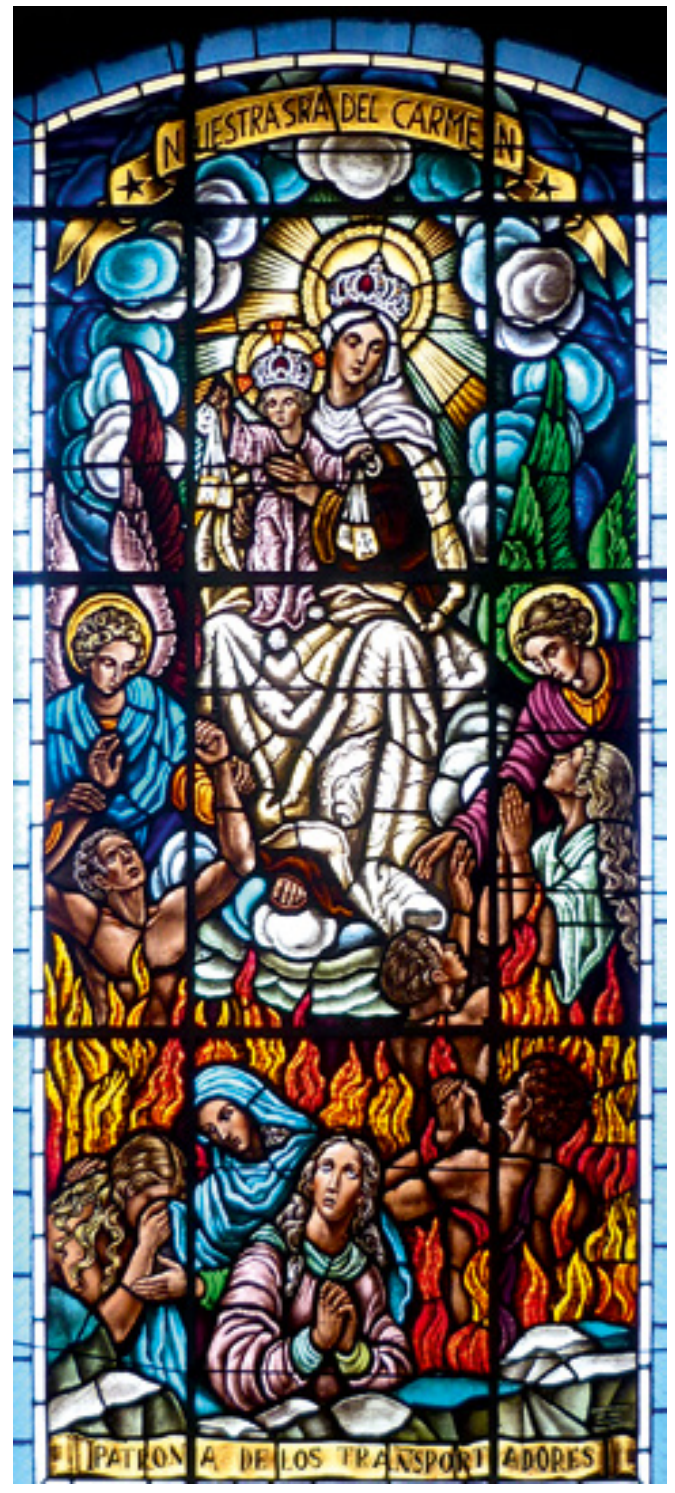

Figura 1. Vitral con la imagen de la Virgen del Carmen en la Catedral de Duitama. Fuente: fotografía del autor. 
La fiesta de Nuestra Señora del Carmen se celebra el 16 de julio, pues según la tradición, en el año 1251 la Virgen María se apareció a San Simón Stock, General de la Orden, en el convento de la ciudad de Cambridge (Inglaterra). Stock, cansado y debilitado por la penitencia, pedía a Dios aliviar su padecimiento. Se dice que:

\section{Suplicaba a la Virgen que lo socorriera con una gracia especial. Ella, ante el llamado suplicante de su hijo, apareció rodeada de ángeles, con el escapulario en sus manos. Le dijo: "Recibe, hijo mío amadísimo, esta prenda de mi amor para con vosotros; este será un privilegio para ti y para todos cuantos lo usen. Quien muera con él no irá al fuego del infierno" (Catholic.net, 2017).}

A partir de entonces nace la imagen de la advocación de Nuestra Señora del Carmen, en que el Niño y la Madre cargan el escapulario, distintivo de la comunidad carmelita. El escapulario marrón, distintivo externo de esta imagen, es según el Concilio Vaticano II un signo sagrado, "por medio del cual se da significación a lo espiritual; se menciona que ha tenido épocas de mayor florecimiento y épocas de menor popularidad. Hoy, esa popularidad y ese florecimiento, son, intensa y extensamente, fuertes y entrañables" (Blanco, 2017, pág. 579).

\section{Descripción iconográfica de la Virgen del Carmen}

La imagen de la Virgen del Carmen se compone de dos personajes. El primero es ella misma, advocación que en su mayoría se presenta con el atuendo de una monja carmelita, con un traje largo y oscuro y cubierta por un manto de color beige, que va desde su cabeza hasta sus tobillos. Su túnica de color café significa humildad, pues esta palabra proviene del vocablo latino humus, cuyo significado es tierra. Por tal motivo, los hábitos de los monjes son de ese color. Sobre su cabeza lleva una corona, representación de su condición de Reina, Señora y Madre del Rey, del Hijo de Dios. En su brazo izquierdo tiene el usual escapulario, elemento primordial en esta representación mariana. Su posición corporal varia, pues puede aparecer de pie o sentada, con la cabeza despejada. El rostro tiende a ser ovalado, el conjunto facial es muy maternal y su semblante irradia calma. Los pies están descalzos, característica esencial de la congregación religiosa de los carmelitas, quienes a partir de una reforma de Santa Teresa de Jesús y San Juan de la Cruz buscaban retornar a la vida centrada en Dios, con toda sencillez y pobreza. 
El otro personaje es el niño, quien reposa sobre el brazo derecho de la Virgen. También lleva una corona sobre su cabeza, tiene sus brazos extendidos y en cada una de sus manos sostiene un escapulario. Suele vestir túnica de color rosado, el cual proviene del rojo que es masculino y denota el fuego de la caridad, el martirio por amor y la sangre derramada por Cristo. El rosa es el pequeño rojo de los niños varones. Asimismo, es frecuente verlo vestido de blanco, color que irradia pureza.

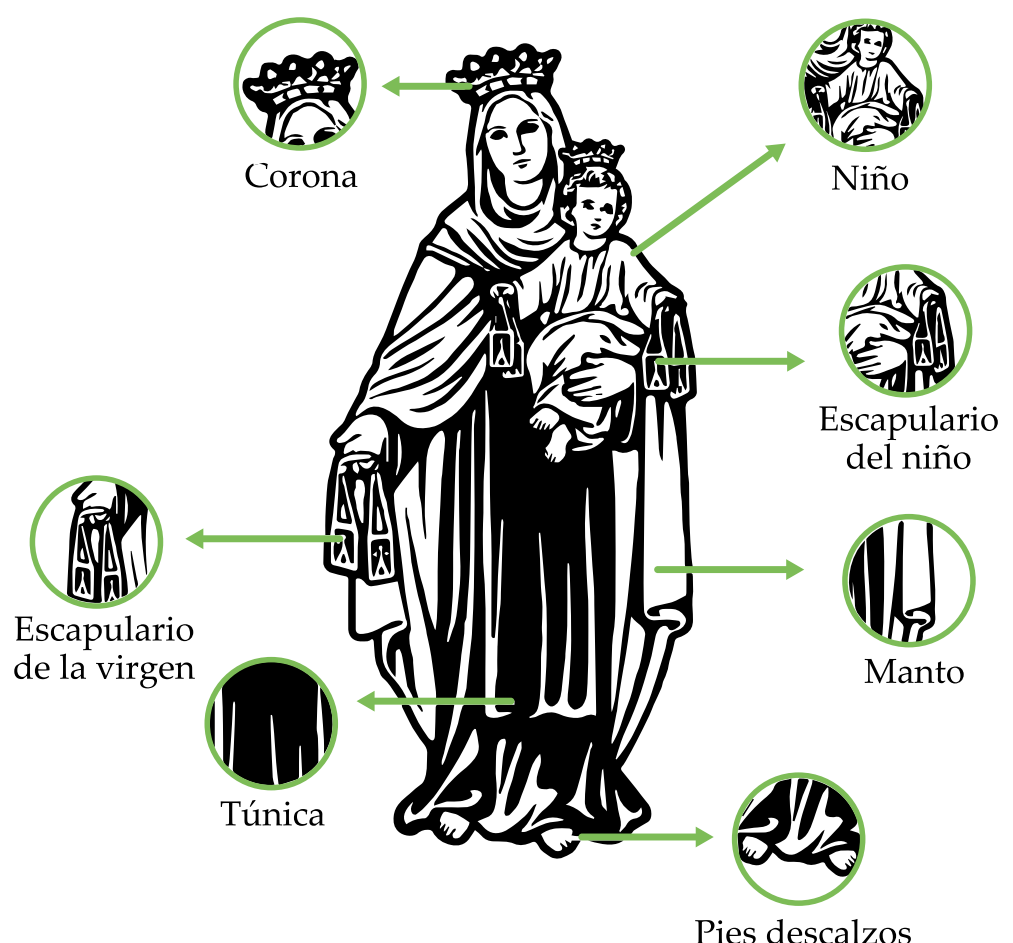

Figura 2. Iconografía de la Virgen del Carmen. 


\title{
La festividad en honor a la Virgen del Carmen
}

Aunque es una fiesta de origen occidental ligada al mar y las embarcaciones, llega a Colombia a partir de los procesos de mestizaje y es adoptada por los transportadores. En la Colonia, cuando los indígenas fueron sometidos a los rigores del poder español que buscaba el control del territorio y el adoctrinamiento al catolicismo, la evangelización estuvo marcado por imágenes de la Virgen como elemento de diferenciación. Para comprender la incidencia de estas nuevas creencias y el sincretismo en los territorios americanos, Gruzinski (2007) plantea:

\begin{abstract}
El cristianismo del Renacimiento era un modo de existencia antes que un conjunto bien definido de creencias y de rituales: englobaba la educación, la moral, el arte, la sexualidad, las prácticas alimenticias y las relaciones de alianza (...) Por todas estas razones, la cristianización constituyó un eslabón esencial en la occidentalización del Nuevo Mundo. Los instrumentos de esta conversión revelan la diversidad de las estrategias que los monjes desarrollaron para someter a los vencidos a su ley y hacer de ellos cristianos (p. 112).
\end{abstract}

En este sentido, la configuración de las creencias cambia y se construyen nuevos espacios y otras formas de religiosidad. Para entender estas prácticas, se parte del presupuesto que primero es preciso comprender la religiosidad popular y cómo esta se ha mezclado con la herencia española para generar costumbres que han adquirido importancia en la cultura popular y en la producción de formas visuales. En Duitama, el escapulario se hace presente en la decoración de los vehículos de transporte, en una estética particular que refuerza las prácticas culturales al proveer de significado a estos objetos. $\mathrm{Al}$ respecto, es claro que:

Las prácticas religiosas varían enormemente por relación al grado en que explicitan la ideología de la que reciben sentido. Muchos aspectos de esta explicitación son puramente no verbales: existe un sistema de gestos y movimientos pautados, generalmente elaborados en forma de danzas; se dan también manipulaciones de los objetos de culto, las manufacturas y el uso de los indumentos y parafernalia; están, por otro lado, las ofrendas y los sacrificios; las reglas sagradas sobre el tiempo y el espacio, y los objetos decorativos y artísticos, entre los que se incluye la música y la arquitectura (Schwimmer, 2006, p. 75). 
La fiesta de la Virgen del Carmen en Duitama tiene una configuración establecida. Se inicia con una procesión de automotores decorados con globos, serpentinas, imágenes de la Virgen y escapularios. Enseguida se realiza la eucaristía y se culmina con un rito especial consistente en la bendición de los vehículos.
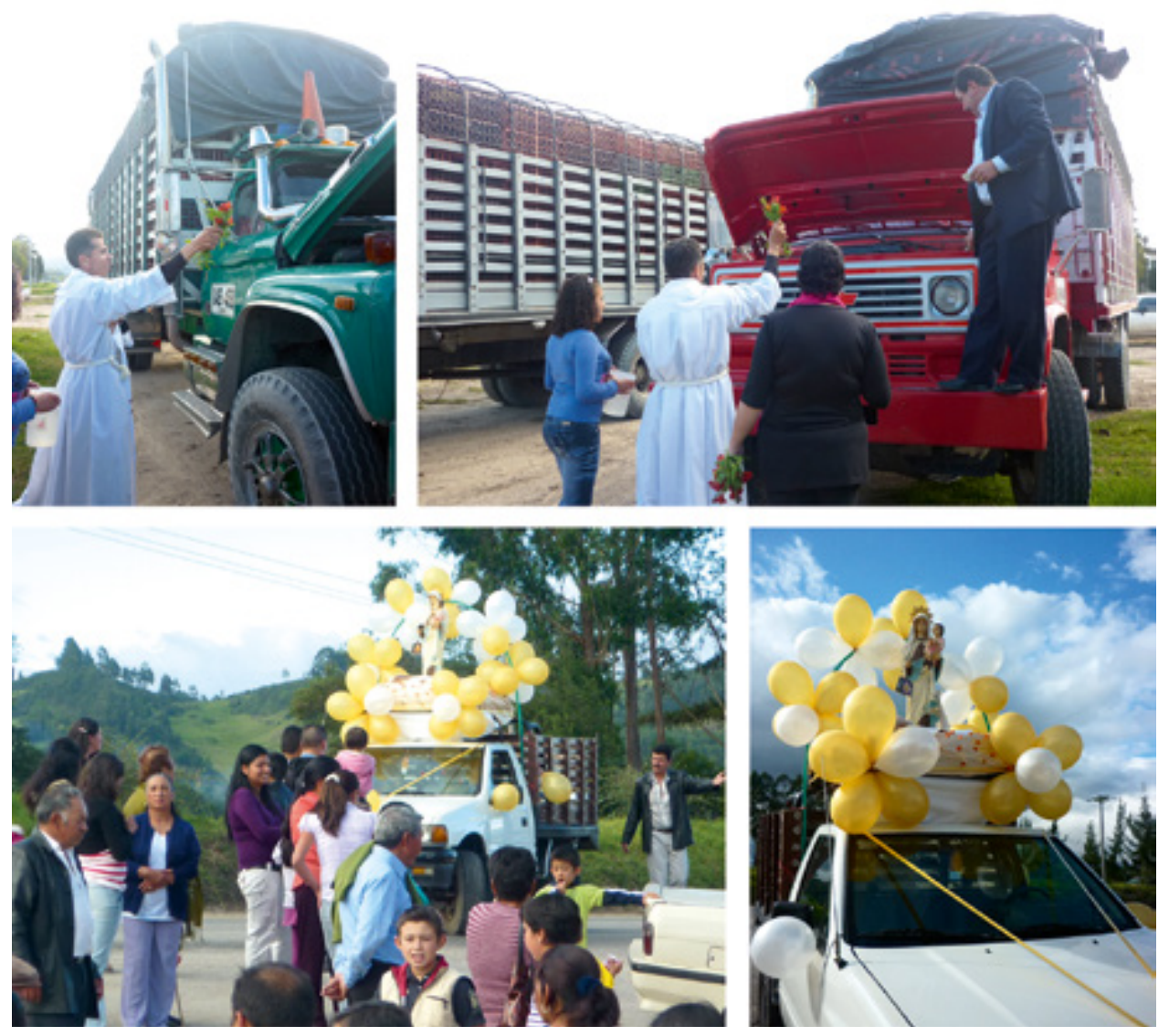

Figura 3. Celebración de la Virgen del Carmen en la ciudadela en Duitama. Fuente: fotografías del autor. 
Dado que las prácticas religiosas y sus expresiones tangibles hacen parte esencial de los procesos de comunicación y significación, estas construcciones adquieren valor cuando se llevan a espacios colectivos, pues de esta forma se evidencian como resultado de imaginarios que se reinventan y evolucionan constantemente.

Dichos elementos pueden ser objetos de estudio que permiten indagar en torno a las manifestaciones de la cultura popular y sirven de fuentes en la configuración de mensajes visuales. En el caso del escapulario, la iglesia católica ha impulsado el uso de este objeto con el fin de recordar el compromiso con la iglesia, de modo que la forma se convierte en una guía de contenidos simbólicos. De hecho

\footnotetext{
El arte, y el significado del arte, la forma y la función del componente visual de la expresión y la comunicación han cambiado radicalmente en la era tecnológica, sin que se haya producido una modificación correspondiente en la estética del arte. Mientras el carácter de las artes visuales y sus relaciones con la sociedad y la educación se han alterado espectacularmente, la estética del arte ha permanecido fija, anclándose anacrónicamente en la idea de que la influencia fundamental para la comprensión y la conformación de cualquier nivel del mensaje visual debe basarse en inspiraciones no cerebrales (Donis, 1985, p. 5).
} 
Comprender cómo genera la cultura popular formas específicas de comunicación visual demanda mecanismos para examinar la configuración y producción de esas construcciones simbólicas. Para abordar sus formas de elaboración y los escenarios donde se gestan, es preciso tener en cuenta que tales prácticas responden principalmente a expresiones culturales ancladas en tradiciones de gusto popular.
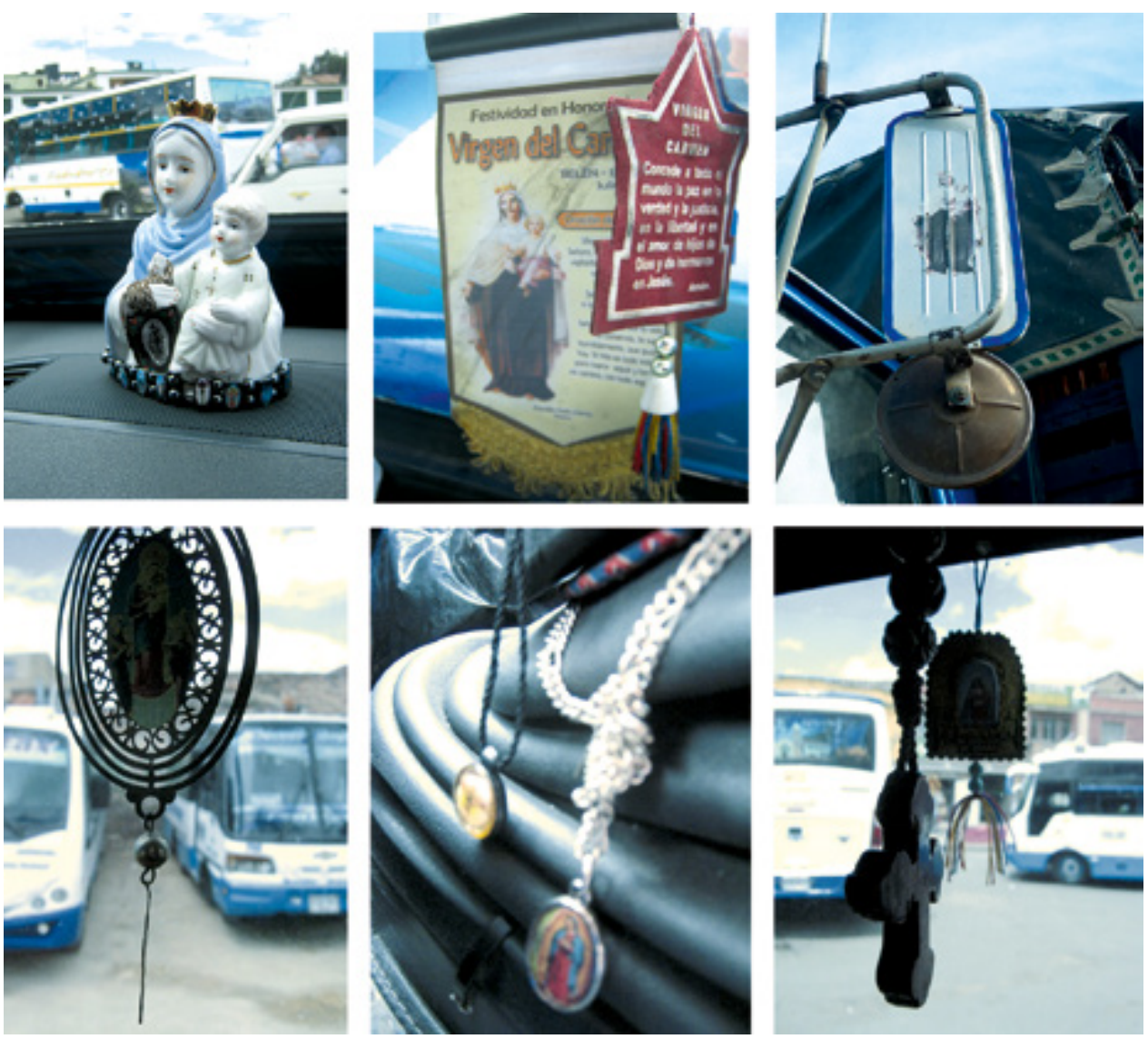

Figura 4. Elementos decorativos religiosos presentes en buses de rutas urbanas en Duitama. Fuente: fotografías del autor. 
Esta inspiración para los mensajes se traduce en imágenes que dan significado a los espacios donde las prácticas de culto trascienden los lugares religiosos. La creencia se traslada al transporte dado que el vehículo es fuente de ingreso para la población.

\section{EL ESCAPULARIO}

Es un objeto indisoluble unido a las prácticas religiosas, símbolo material de la devoción hacia la Virgen del Carmen en el que se reflejan diferentes matices de las creencias de la cultura popular. En términos generales, se define como:

\section{Un objeto devoto formado por dos trozos de tela en los cuales va pintado, bordado, pegado o guardado un objeto venerado o una imagen, unidos por dos cintas o cordones que los mantienen colgados de los hombros, uno sobre el pecho y otro sobre la espalda (Figueroa, 2001, p. 147).}

Por consiguiente, encuadra en la categoría de objeto de naturaleza creyente. En un principio fue una prenda de uso restringido a ciertas órdenes religiosas, por lo cual terminó dotando de significado a un hábito en particular. Las comunidades religiosas se siguen identificando a partir del vestuario y llevan su hábito como signo de consagración. Luego, el escapulario se comercializó como prenda, manteniendo las mismas características de los religiosos, pero reducido en tamaño. Se dice que "para ganar las indulgencias se requiere que el color del escapulario del Carmen sea atezado, color café, pardo, negro u otro semejante" (Herradón, 2001, p. 155). Junto con el rosario y la medalla milagrosa, es un elemento principal en la iconografía mariana. Actualmente, puede observársele conformado por dos piezas pequeñas de tela generalmente de color café, cuyas formas oscilan entre cuadrados y óvalos, y al interior de ellas se ubica una imagen, ya sea la Virgen, Jesús o San José.

Se trata entonces de un objeto significante portado por los devotos como parte de su ofrecimiento y creencia, al tiempo que evidencia el ingreso o la participación en la cofradía que comparte las ideas de los Carmelitas. Igualmente son importantes los ritos acompañantes al hecho de llevar este elemento. La norma principal al respecto refiere la imprescindible bendición del escapulario, por lo tanto, en la celebración de la fiesta a la Virgen del Carmen no falta este acto de consagración. 

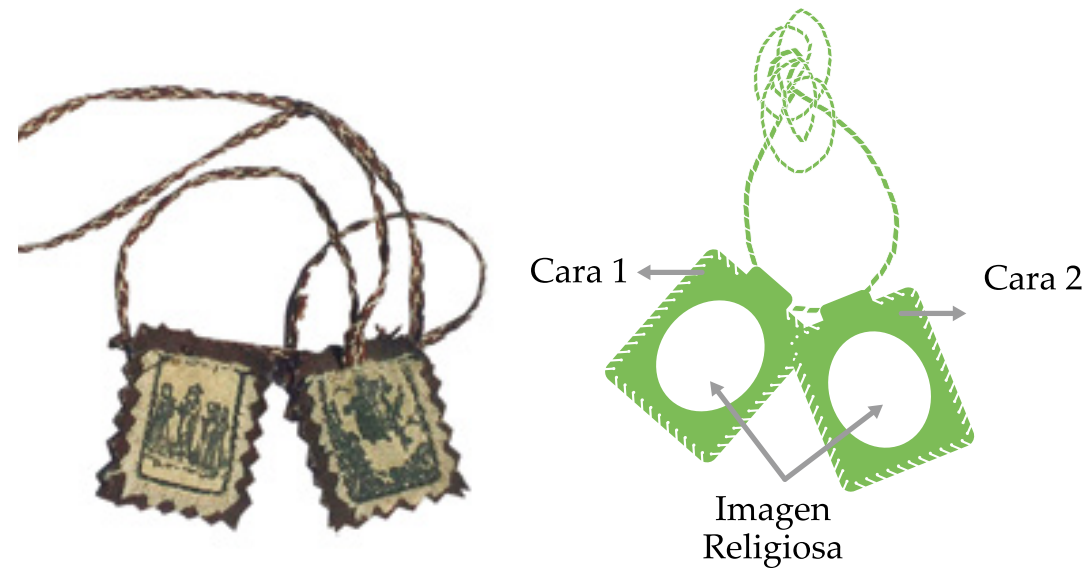

Figura 5. Partes del escapulario.

Fuente: autor.

\section{La noción de amuleto}

Los amuletos son objetos simbólicos usados para conseguir protección y bienestar, como también para actuar efectivamente en la transmutación de energía. Pueden representarse a través de imágenes o figuras y son una consecuencia del pensar mágico y de los fenómenos circunstanciales a la historia humana. La celebración de rituales, el empleo de estos elementos y de talismanes son respuestas a un valor universal humano, como es la necesidad psicológica de prevención y protección. Así, sirven de símbolos tangibles de esperanza que fortalecen las creencias de cada quien. Se dice que los griegos veneraban las reliquias de sus héroes, tradición recogida por los romanos y con prácticas similares en el culto cristiano. De tal modo, varias combinaciones se han generado a partir de herencias del mundo pagano.

En estas prácticas sociales se refuerzan las tradiciones y creencias populares, se genera una lucha por validar determinados valores culturales, y los individuos construyen colectivamente imaginarios de protección a través de la legitimación de los objetos. "La construcción imaginaria pasa así por múltiples estandartes de narración ciudadana, pero por debajo de todos sus relatos corre, como fuente de un acontecimiento psíquico, la figura oscura y densa del fantasma social" (Silva, 2000, p. 98). Hay entonces implicaciones simbólicas, pues los rituales se fortalecen a partir de la validación de los objetos y la forma en que los sujetos construyen y 
fortalecen sus creencias, a partir de la idea de protección buscada con la realización de los rituales. Respecto a esa relación formal afirma García Canclini (2009), uno de los investigadores más importantes de la interculturalidad en América Latina:

\begin{abstract}
Entender las relaciones indispensables de la modernidad con el pasado requiere examinar las operaciones de ritualización cultural. Para que las tradiciones sirvan hoy de legitimación a quienes las construyeron o las apropiaron, es necesario ponerlas en escena. El patrimonio existe como fuerza política en la medida en que es teatralizado: en conmemoraciones, monumentos y museos (p. 151).
\end{abstract}

En el mundo actual, donde cada vez se fragmentan más los procesos culturales que configuran la cultura popular, la lectura de los imaginarios colectivos y de las manifestaciones visuales presentes en las expresiones de la fiesta popular permite descubrir y valorar rasgos significativos de dichas prácticas. Los eventos, las creencias y su significado favorecen este análisis. El empleo de objetos simbólicos que cumplen la función de amuleto, en este caso el escapulario, se convierte en una expresión significativa en términos de producción visual. A su vez, cabe resaltar: “las imágenes simbólicas se equilibran entre sí con mayor o menor precisión, más o menos globalmente, según la cohesión de las sociedades y también según el grado de integración de los individuos en los grupos" (Durand, 1968, p. 117).

Ese imaginario de protección y sus expresiones hacen parte de los procesos de validación de las creencias que se ratifican en los actos ceremoniales de bendición, en este caso de los automotores, cuando los creyentes adornan sus vehículos con imágenes y elementos simbólicos que generan procesos de significación.

Estas construcciones toman fuerza cuando adquieren una expresión colectiva, pues son el resultado de prácticas sociales que se reinventan constantemente, según tendencias y estilos. Los imaginarios pueden entenderse como construcciones sociales generadas por los habitantes de un lugar, así como las ideas y percepciones surgidas al ejecutar determinadas prácticas y otorgarles un poder simbólico. "En el irremediable desgarramiento entre la fugacidad de la imagen y la perennidad del sentido que constituye el símbolo, se refugia la totalidad de la cultura humana como una mediación perpetua entre la esperanza de los hombres y su condición temporal" (Durand, 1968, p. 140). En la relación simbólica dada a partir de la imagen de la Virgen del Carmen, el acto ceremonial y la magnificación del escapulario como elemento protector, se gesta un conjunto de acciones en que el participante es un validador y lo visual se convierte en afirmación del acto de fe. 


\section{Configuración formal del escapulario}

En el acercamiento al objeto de estudio es necesario analizar el escapulario desde el diseño con el fin de identificar sus elementos compositivos. El diseño ha tenido gran incidencia en la historia humana. El hombre ha descubierto la utilidad de los instrumentos y ha desarrollado objetos con propósitos utilitarios y simbólicos para satisfacer necesidades tanto materiales como religiosas. Si se tiene en cuenta que "la relación diseño-objeto práctico funcional es de este orden: por un lado, el diseño mitifica al objeto y, por el otro, provee a los mitos sociales de apoyos concretos de los cuales nutrirse" (Arfuch, 1997, p. 33), es pertinente comprender las formas particulares de producción visual inmersas en las culturas populares que al ser abordadas evidencian su impacto en la configuración de prácticas simbólicas.

El escapulario parte de formas básicas y aunque su historia data de tiempos pasados, cuando probablemente no se consideraban elementos compositivos sino especialmente simbólicos, cuenta con una estructura que funciona y puede leerse como sigue. Su construcción por lo general es un rectángulo en cuyo centro aparece un óvalo o un círculo dispuesto de modo tal que ejerce una tensión visual en cuanto a composición y forma con respecto al centro, es decir, a la imagen.
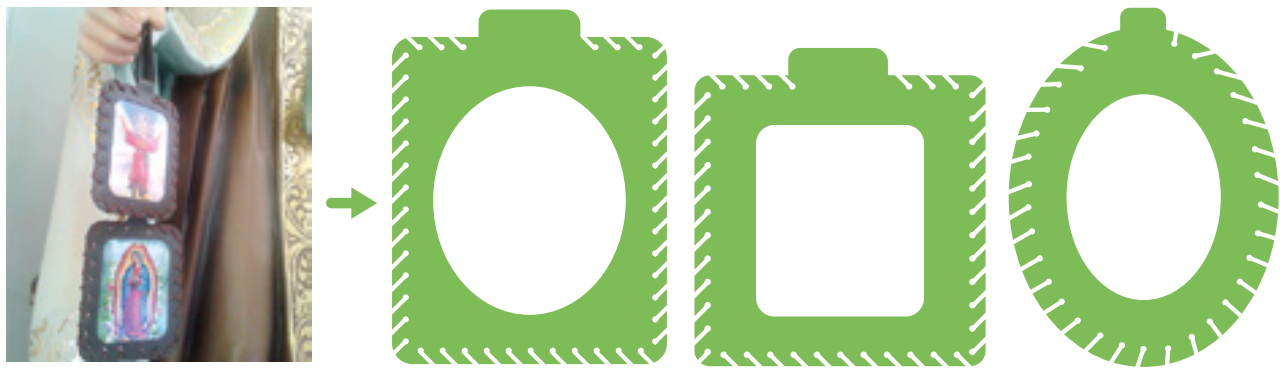

Figura 6. Diagramas de escapularios.

Fuente: autor. 
$\mathrm{Al}$ respecto, se estima que:

La experiencia visual es dinámica (...) Lo que una persona o un animal percibe no es sólo una disposición de objetos, de colores y formas, de movimientos y tamaños. Es quizás, antes que nada, un juego recíproco de tensiones dirigidas. Esas tensiones no son algo que el observador añada, por razones suyas propias, a las imágenes estáticas. Antes bien, son tan intrínsecas a cualquier precepto como el tamaño, la forma, la ubicación o el color. Puesto que tienen magnitud y dirección, se puede calificar esas tensiones de "fuerzas" psicológicas (Arnheim, 2010, p. 26).

Es preciso recordar que, tanto en lo visual como en lo físico, el equilibrio es el estado de distribución en que toda acción se ha detenido. En una composición equilibrada, todos los factores del tipo de la forma, la dirección y la ubicación se determinan mutuamente y no parece posible cambio alguno. Los componentes presentes en el escapulario (forma, color y ubicación) están ordenados para expresar sensaciones favorables. Su distribución se realiza en función de una estructura dotada de una significación clara y de una intención conveniente con el mensaje a transmitir.
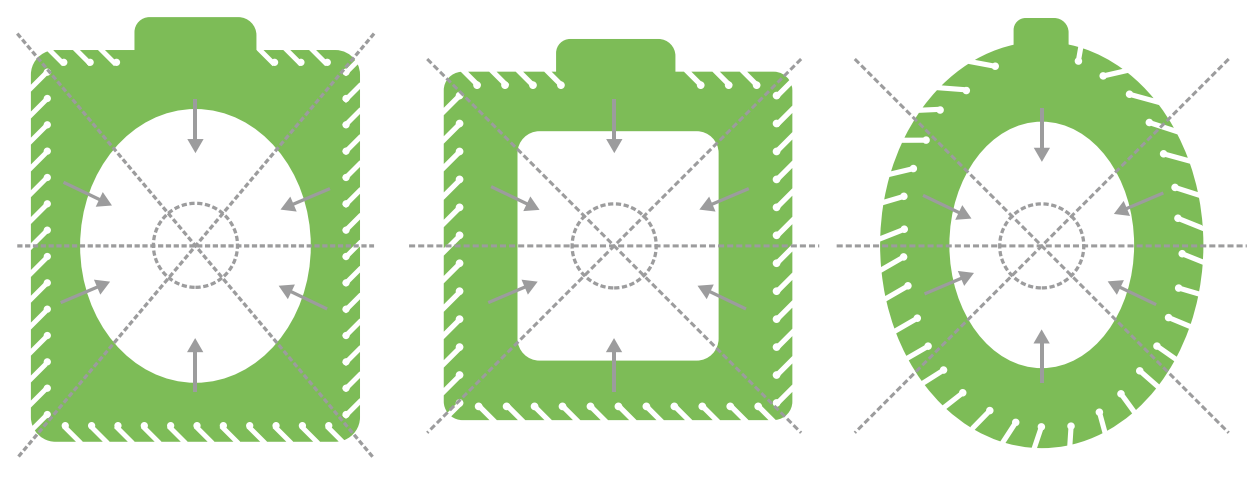

Figura 7. Esqueleto estructural de los escapularios.

Fuente: autor. 
Al plantearse una estructura compositiva o al analizar una composición, es preciso tener en cuenta varios conceptos: encuadre, formato, centros focales, angulación, color, luminosidad y contexto, como también la propia estructura resultante de la diagramación de todos estos elementos. Para Arnheim (2010), "estas inducciones perceptuales difieren de las inferencias lógicas. Las inferencias son operaciones del pensamiento que, al interpretarlos, añaden algo a los datos visuales dados. Las inducciones perceptuales son a veces interpolaciones basadas en conocimientos previamente adquiridos" (p. 27). La información en la estructura del escapulario busca fortalecer esa imagen central, previamente reconocida entre la población.

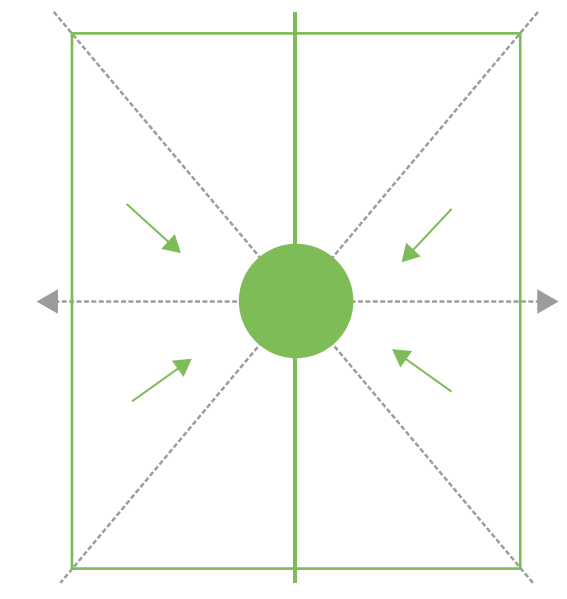

Figura 8. Esqueleto estructural del cuadrado.

Fuente: autor.

De tal manera, el contacto visual con el objeto genera experiencias perceptuales hacia los datos visuales transmitidos. Se producen situaciones subjetivas en que el mensaje actúa en el inconsciente, ayudado por una estructura compositiva que en este caso es estable al coincidir con el eje de la composición y motivar una atracción directa hacia el centro. De tal forma, el diseño influye en la percepción y logra una mejor comprensión del mensaje. En esta comunicación, el intercambio de ideas sirve como guía y apoyo en la construcción eficiente del imaginario colectivo.

En el esqueleto estructural del cuadrado (figura 8), la estructura influye no solo en los límites o bordes de la forma y su centro, sino también en el esquema cruciforme dado por los ejes centrales (vertical y horizontal) y las diagonales. El centro se convierte en la principal atracción al quedar determinado por el cruce de esas cuatro líneas estructurales. Así, fácilmente se puede determinar el poder de atracción. 
Aunque la figura central es la Virgen del Carmen -imagen de gran reconocimiento e influencia en las creencias populares- el escapulario no tendría sentido como elemento cargado de poder y protección si no fuera parte de la iconografía de esta advocación. En este intento por analizarlo desde el diseño e identificar su fundamentación en las creencias populares y su interacción con los devotos, debe considerarse entonces la producción simbólica de imaginarios, lo cual permite comprender las implicaciones de una estética en particular y de la cultura visual que trae consigo. Desde tal enfoque, las prácticas populares se convierten en contenedores de intercambio cultural en las que:

\begin{abstract}
Emociones cotidianas y signos comunes se adhieren a la superficie de los diseños: los embozan o los arropan con aquellas metáforas que más convienen al sistema de creencias de las comunidades a las que pertenecemos; con aquellas ideas más adecuadas a la interpretación de los verosímiles que, a su vez, a través de los objetos vivimos y generamos (...) Si bien un diseño está designado culturalmente-configurado por metáforas provenientes de alguna comunidad específica-, cuando es adoptado, escogido o recibido como un bien, y luego durante el uso hasta ser descartado, es siempre un diseño individualizado: un objeto que se "singulariza" en un papel doméstico o ritual particular (Juez, 2002, p. 140).
\end{abstract}

En la experiencia perceptual, este esquema estimulador determina el papel de cada elemento dentro del sistema de equilibrio y sirve de marco de referencia para definir el valor de los componentes. La figura y la estructura conforman una composición dinámica con un centro de fuerza atractiva, cuya influencia va más allá de sus entornos, dentro y fuera de los límites de la figura. El centro pasa a ser el punto más importante, pues allí recae la mirada. Es una composición básica y balanceada, con conexión entre la función comunicativa y la simbólica. Como señala Arfuch (1997) puede decirse que el diseño ha pasado por un proceso de síntesis y depuración:

El Diseño se levanta contra el modo previo de articulación entre instrumento
y símbolo y propone una nueva síntesis donde los elementos de la sintaxis
técnica y ergonómica adoptan ellos mismos una función simbólica y estética.

El diseño nace como un proceso de síntesis de todos los condicionamientos de la forma, mediante la cual estos planos resultan, en el producto final, indiscernibles. La mera adjetivación es sustituida por la configuración de unidades complejas en las que se entrelazan funciones igualmente sustantivas (p. 107). 
En este análisis del escapulario se puede ver en el diseño no solo un ornamento o un recurso para transmitir una apariencia agradable. Es un proceso de creación con un propósito en que la expresión visual debe tener particularidades propias. Se aprecia que la relación espacial en el contenedor (el cuadrado) es eficiente y tiene carácter. Allí, los objetos se perciben dotados de un determinado tamaño y no como algo aislado. La experiencia visual es dinámica pues además de una disposición de objetos, colores y formas, este conjunto conlleva una relación de tensiones dirigidas. La imagen en el óvalo está conducida hacia el centro del cuadrado y su posición es más estable cuando su propio centro coincide con el del cuadrado. En consonancia con lo expresado por Costa (1998, p. 98), en este ejercicio de percepción:

\section{El conjunto de situaciones en las que la mente humana se ve conducida a pensar "lógicamente" constituye en realidad una pequeña fracción de las situaciones reales de la vida, lo que no significa que la mente no reaccione ante los elementos de la situación de un modo regular y parcialmente previsible: percepción visual o sonora, recepción publicitaria o de los medios, recepción de una estructura retórica.}

Aunque el usuario construye un esquema de información percibido a través de los órganos sensoriales, en el diseño de esta pieza cada uno de sus elementos compositivos tiene importancia para lograr que el mensaje sea comprendido y los datos visuales interpretados. El ojo como órgano no ocupa el centro de atención, pues este recae en el acto de ver, entendido como proceso holístico y sistema complejo de percepción: ver, entender, reconocer, pensar. Así, los procesos perceptuales se dan a partir de funciones con características asociadas a la forma concreta como las personas visualizan los objetos, sin dejar de lado que desde el diseño estos se configuran para sacar provecho a su poder compositivo.

\section{RITUAL RELIGIOSO Y TRANSPORTE}

\section{Percepción de los transportadores}

De acuerdo con el objetivo planteado en la investigación, se utilizaron instrumentos para explorar entre la población la manera como los objetos religiosos configuran tradiciones, creencias y mitos populares. Se recurrió a la técnica de la observación, soportada en el registro fotográfico y el diario de campo. Asimismo, para obtener la percepción del grupo específico de los conductores de transporte público, se aplicó un cuestionario que incluyó datos básicos orientados a identificar, categorizar y diferenciar a los encuestados, junto a ocho preguntas cerradas y dos abiertas. 
Las relaciones construidas a partir de la apropiación y ritualización de los vehículos están ligadas directamente a la decoración con imágenes provistas de simbolismo. "La imagen siempre ha tenido fuerza en la conformación de los imaginarios colectivos: baste recordar el peso que tiene para las tres grandes religiones monoteístas" (Arfuch, 1997, p. 77). De tal manera, la conexión entre el sujeto y sus percepciones evidencia relaciones simbólicas dentro de la cultura popular. En este caso, mediante el uso simbólico del vehículo como forma de mantener tradiciones y reiterar creencias, el rito une lo individual y lo colectivo dado que:

\footnotetext{
Todo cuanto el hombre percibe son primariamente sensaciones de un mundo sin significados, que él traduce de acuerdo con su espíritu y su sistema psíquico, y las transforma en objetos significativos, intelectuales y emotivos. Estos objetos son utilizados por el hombre para resolver sus problemas físicos y psíquicos; los primeros dan lugar a la creación de instrumentos funcionales (cobijo, alimentos, vestidos) con los que atiende a sus necesidades elementales de protección y subsistencia; los segundos producen también sus instrumentos específicos, mágicos, o trascendentes (objetos de exorcismo y propiciación), con los que intenta conciliar un equilibrio entre las necesidades de su espíritu y las circunstancias del mundo exterior: estos objetos son los símbolos (Costa, 1971, p. 39).
}

Los resultados de la investigación reflejan construcciones simbólicas y creencias frente a prácticas en que se reconocen imaginarios y se valoran procesos fortalecedores de la cultura popular. Al indagar por la percepción respecto al escapulario, más allá de identificar los objetos de ritualización de la población, se apuntó a una lectura de las prácticas enmarcadas en una ritualidad históricamente asociada a determinadas creencias dentro del marco de la cultura popular. 
Para entender el valor de la percepción al estudiar el escapulario, es pertinente diferenciarla de la sensación. Esta última se refiere a experiencias inmediatas básicas y sus respuestas, generadas por algún tipo de estimulación. Por su parte, la percepción consiste en interpretar y proveer de significado esas sensaciones. Tal interpretación implica la actividad de los órganos sensoriales y el cerebro.

Toda percepción es un acto de búsqueda de significado, y, en este sentido,
es un acto de comunicación o de búsqueda de comunicación. La función
biológica de la percepción visual es la de proveer información acerca del
medio ambiente en función de asegurar la subsistencia (...) la percepción
está conectada con el más poderoso de los instintos animales: el instinto
de conservación. Teniendo esto en cuenta y considerando que el hombre
es fundamentalmente visual, es fácil entender la fuerza que los mensajes
visuales pueden tener, aunque su contenido no sea importante: es el canal
lo que concede la potencia (Frascara, 2000, p. 61).

${ }^{2}$ Cfr. Declaración Universal de los Derechos Humanos, artículo 18.
Sobre la base de la declaración de garantías respecto a la libertad de pensamiento, conciencia y religión ${ }^{2}$, en Colombia existe la libertad de culto. La colonización española trajo consigo, entre otras realidades, la predicación del catolicismo, a partir del cual se generaron creencias y prácticas como parte del mestizaje y en un proceso de sincretismo. La globalización y distintas ideologías han llevado, a su vez, al surgimiento de nuevos cultos, cuyos adeptos pueden practicarlos libremente.

En este contexto, la encuesta aplicada indagó por la religión con que se identifican los transportadores. La figura 9 ilustra la fuerte tendencia hacia el catolicismo en las respuestas. El 95\% de los encuestados se identifica con esta religión y el 5\% tiene creencias de origen cristiano. A su vez, ambos grupos se consideran creyentes alta y medianamente activos en un $48 \%$, y poco activos en un $4 \%$. 


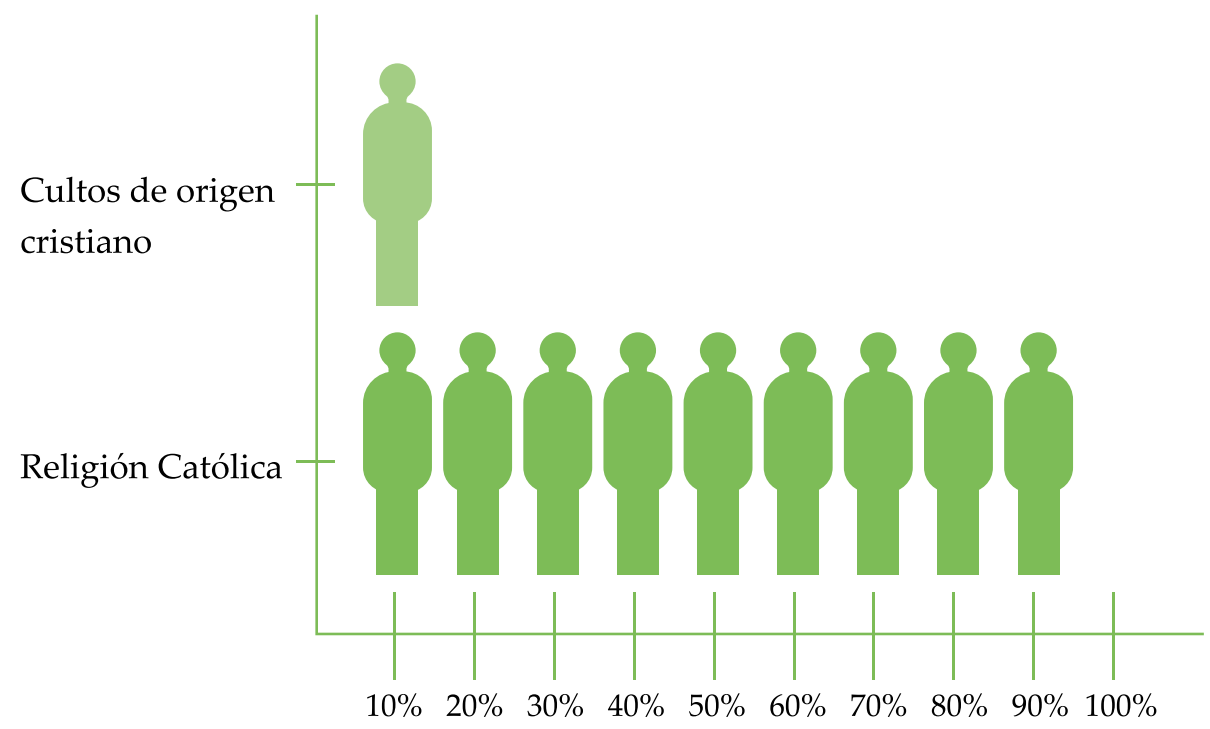

Figura 9. Resultados de la encuesta para la pregunta sobre identificación religiosa.

Fuente: autor.

En estos colectivos la religión incide notoriamente en sus actitudes, costumbres y motivaciones. Cabe retomar la definición dada por Geertz a la religión:

Un sistema de símbolos que actúa para establecer en los hombres, potentes, persuasivas y duraderas actitudes y motivaciones, mediante la formulación de concepciones generales referidas a la existencia, a las que reviste con tal aura de factualidad que dichas actitudes y motivaciones aparecen como absolutamente realistas (citado en Schwimmer, 2006, p. 10).

La religión siempre ha estado presente en la vida humana. Lo valioso desde el punto de vista de las manifestaciones culturales es encontrar afinidades que den cuenta de correspondencias para entender cosmogonías desarrolladas en el tiempo.

Un alto porcentaje de encuestados se identifica como creyentes católicos. En este sentido puede decirse que la religión fortalece los sistemas de representación y sirve de fuente generadora de emociones, en la medida que los individuos son motivados por sus creencias. El catolicismo tiene una notoria carga motivacional en Boyacá y con la celebración de fiestas en honor a santos y figuras religiosas, año tras año se reviven ritos de arraigo cultural que actúan como sistemas significantes completos. 
Desde sus percepciones, la mayoría de la población vinculada al transporte público referencia las tradiciones como un vínculo clave en la preservación de las creencias. En la figura 10 se muestra que para el 31\% de los encuestados, el sistema de transporte y los conductores se identifican con la Virgen del Carmen debido a la tradición, y por la creencia para el $52 \%$. Según un $17 \%$, a través de esas creencias se mantienen perennes las tradiciones, pues las personas, con pleno conocimiento de las costumbres, favorecen la continuidad y el respeto hacia tales prácticas.

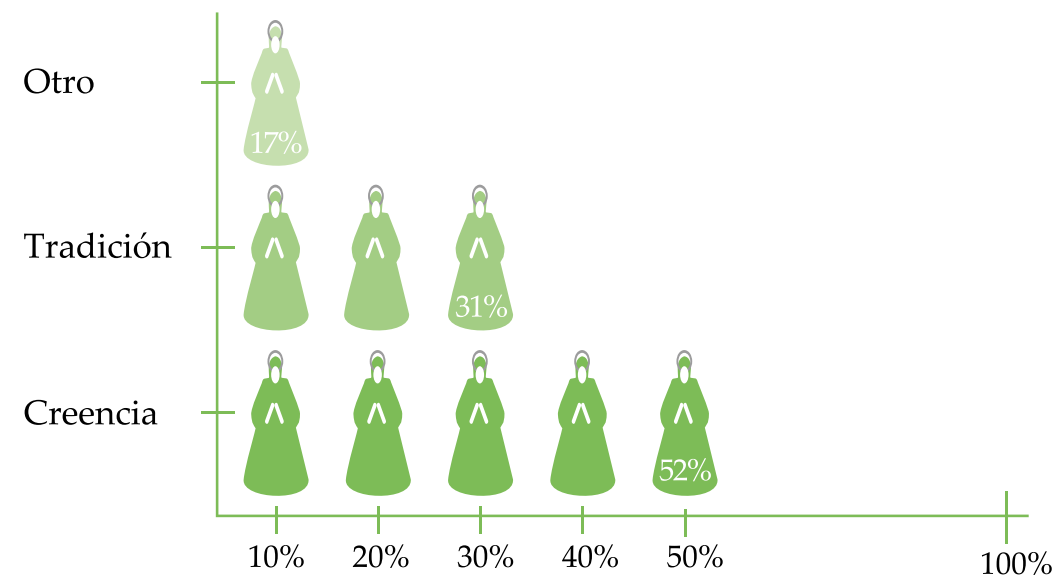

Consideran que el sistema de transporte y los conductores se identifican con la Virgen del Carmen por parte de los conductores y del sistema de transporte.

Figura 10. Resultados de la encuesta para la pregunta sobre identificación del transporte con la Virgen del Carmen.

Fuente: autor.

Este tipo de asociaciones están unidas a imaginarios que permiten contextualizar la manera como las prácticas adquieren dimensiones que trascienden su espacio ceremonial particular al establecerse directamente en los vehículos y resignificar ese otro espacio donde la creencia toma valor. Al mismo tiempo, se da cumplimiento a la norma ligada a los Carmelitas respecto a la imprescindible bendición del escapulario. De tal modo, esta tradición recobra fuerza a partir de la herencia, continúa profundamente conectada con sus prácticas asociadas y se mantiene vigente como una necesidad. De manera simultánea se siguen las instrucciones dadas por la Orden religiosa y se conserva un legado de la cultura popular. 
Una pregunta que exploró la noción de rito fue: dentro de su profesión como conductor, ¿suele realizar algún ritual antes de iniciar la labor diaria? En la figura 11 se aprecian los porcentajes para cada opción de respuesta. Las prácticas rituales más recurrentes son la oración, la bendición y la encomendación.

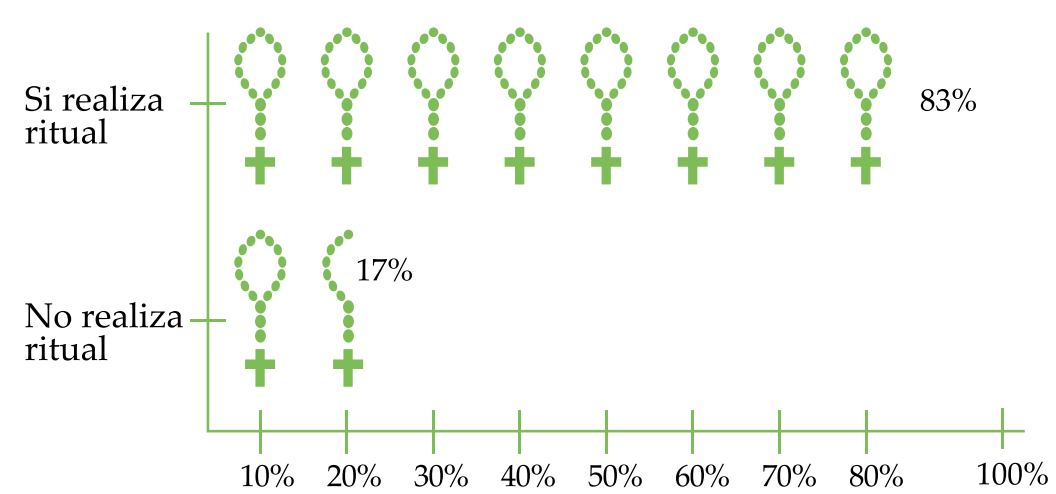

Las prácticas rituales más utilizadas son la oración: la oración, bendición y enconmendación.

Figura 11. Resultados de la encuesta para la pregunta sobre rituales en la labor de los conductores.

Para los encuestados, los rituales son expresiones valiosas dotadas de significado. Actos como persignarse (hacer la señal de la cruz, una en la frente, otra en la boca y otra en el pecho), orar, encomendarse a la Virgen y besar el escapulario, se traducen en convenciones para lograr acompañamiento y seguridad durante la jornada laboral. La percepción y el uso de las sensaciones en estas prácticas rituales se vinculan con el objeto de esta investigación en su conjunto, es decir, las cargas significativas. Sobre este particular, cabe volver a Costa (2003): “El hombre es un animal simbólico. Algunos signos simples han atravesado la historia. El tiempo los ha cargado de sentido porque los hombres han proyectado en ellos sus miedos, sus sueños y sus quimeras, y así se han convertido en símbolos" (p. 116). 
La herencia y la creencia son determinantes en el desarrollo y la permanencia de estas prácticas. La influencia de la imagen y los elementos decorativos como estímulos está ligada más a la tradición, que en este caso se potencia en lo colectivo. El 87\% de los conductores suele decorar los vehículos con imágenes y objetos alusivos a su religión (figura 12), pues dicha decoración entre este gremio tiene como fin estrechar el vínculo con el mundo ceremonial dado por sus creencias.

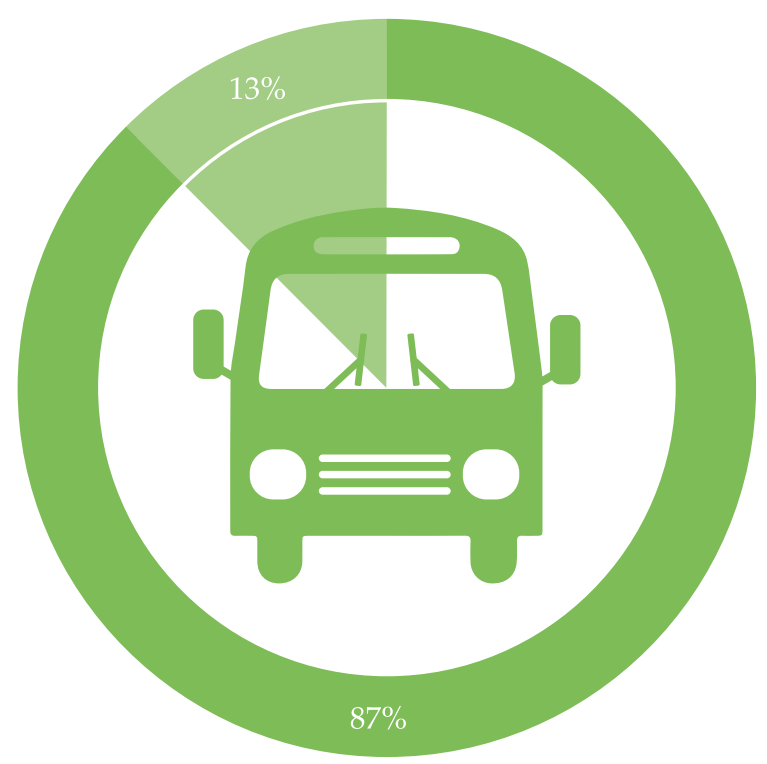

Figura 12. Gráfica de resultados de la encuesta para la pregunta sobre decoración de los vehículos.

Fuente: autor.

Elementos constantes en la decoración son la imagen de la Virgen del Carmen y el escapulario, ambos signos de consagración en que el objeto se vincula con la creencia popular y la devoción religiosa. No es fácil desvincular una devoción de la otra, pues es complicado identificar cuál conexión es más estrecha, si entre el devoto y el escapulario o el devoto y la Virgen. Se trata de "devociones y formas de piedad, unas litúrgicas y otras extralitúrgicas, que manifiestan la religiosidad de un pueblo que tiene su centro en María la Virgen" (Blanco, 2017, p. 591). Históricamente, el escapulario se convirtió en una prenda del vestuario de los devotos. Si bien ha tenido distintos tamaños, con el tiempo se ha venido reduciendo en aras de adaptarse, ya sea como prenda corporal o como objeto decorativo. 
En la figura 13 se ilustra la mediación de los objetos rituales. El 78\% usa el escapulario por protección, el $11 \%$ por suerte y el restante $11 \%$ por superstición. Cobra así valor la gran promesa de la entrega del escapulario a San Simón Stock:

\section{Según la tradición, aborda los acontecimientos de la vida del hombre sobre la tierra, y al comienzo de una vida nueva, de la que van a participar el cielo y la tierra (...) La gloriosa Virgen se le apareció, llevando en sus manos el escapulario y le dijo: Esto es para ti y los tuyos. El privilegio: el que muera con él se salvará (Blanco, 2017, p. 559).}

Igualmente, hay una fuerte convicción en cuanto a los rituales como parte fundamental de la tradición de la fiesta de la Virgen del Carmen. Con estas prácticas se busca sencillamente vivir con felicidad y bienestar, para lo cual se pretende una mediación que provea protección y proyecte la salvación tras la existencia terrenal.

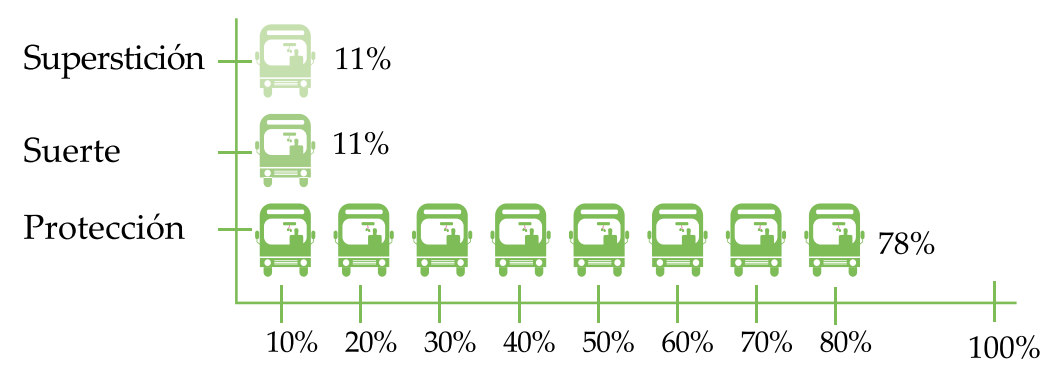

Las prácticas rituales más utilizadas son la oración: la oración, bendición y enconmendación.

Figura 13. Resultados de la encuesta para la pregunta sobre uso de los objetos rituales. 
En esta integración entre la religión, el culto a la Virgen María y la apropiación del escapulario como objeto ritual, en que lo imaginario está sujeto a la sensación y el pensamiento a la función simbólica, se observa un dinamismo relacionado con sucesos en el tiempo. De las estructuras discursivas y de percepción emergen historias asociadas al hábito del escapulario como objeto devocional, las cuales dan como resultado relatos que se vinculan a las construcciones simbólicas en torno a las creencias. El 36\% de los encuestados considera que al tener estas imágenes y objetos en sus vehículos se han protegido de accidentes, el $18 \%$ de todo mal y peligro, y el $46 \%$ difiere entre el peligro, otros problemas y su propia suerte.

Estas prácticas rituales integran al ser humano con su conocimiento y su quehacer diario. La imagen de la Virgen del Carmen y el escapulario constituyen un fenómeno de transmisión y recepción de ideas que responde a una forma de pensamiento individual y configura un imaginario de protección en el colectivo general.

Estas construcciones responden al imaginario que anima el simbolismo en torno a las imágenes de la Virgen y el escapulario, para dar como resultado esquemas dinámicos con fuerzas de cohesión entre la cultura, la religión y el quehacer cotidiano. A través de pautas específicas se identifica el simbolismo cultural transmitido por la herencia. Esta, a su vez, se relaciona con tradiciones estrechamente dependientes del contexto para instaurar prácticas (costumbres, ritos, comportamientos) cuyas cualidades afectivas influyen en la población. La creencia y la utilización de imágenes es una constante generadora de un diálogo que anima, dinamiza y vivifica el simbolismo entre la población de transportadores.

La relación entre la forma y el contenido del escapulario, junto a su mediación como mecanismo ritual y de protección, genera experiencias perceptuales que definen matices y situaciones subjetivas apoyadas inicialmente en el contacto visual con el objeto. La influencia del diseño en esta percepción es evidente, pero es en la imaginación simbólica donde se provee el significado. Así, se legitima la configuración formal del escapulario en un proceso en que el diseño incide en la aproximación al objeto al organizarlo formalmente, en tanto la apropiación se magnifica dado su carácter como portador de significado que lo lleva a situarse entre las narrativas culturales de las creencias y las tradiciones populares. 
Puede decirse que en esta convergencia del diseño y el simbolismo prevalece el hecho de trascender en la historia, de darle sentido a una imaginación simbólica arraigada en la población. Esto hace parte de la actividad dialéctica propia de las culturas, a través de la cual los individuos son animados a mantener vigentes ciertas prácticas, con sus adeptos y oponentes. Al preservar las creencias se genera un dinamismo prospectivo que recurre al imaginario para asegurar el bienestar colectivo. Evidenciar tal diversidad es uno de los valores de estos estudios.

\section{CONCLUSIONES}

Las construcciones simbólicas vinculadas con la fiesta popular de la Virgen del Carmen están dadas por el escapulario como elemento central. La composición y construcción formal de esta clase de imágenes religiosas refuerzan su capacidad de integrar prácticas culturales y de fomentar la simbolización.

En las romerías, fiestas populares y religiosas, la figura central de admiración y devoción es una imagen de un santo o una advocación de la Virgen. En el caso aquí estudiado, aunque la imagen de la Virgen del Carmen tiene gran reconocimiento e influencia en las creencias populares, el escapulario ha adquirido marcada importancia en la iconografía. El análisis de sus elementos compositivos desde la perspectiva del diseño revela su configuración formal, definida por una estructura provista de líneas que confluyen en su centro para marcar una concepción ordenada a través de un esquema perceptualmente sencillo que apoya la virtud de la visión, con la intención de orientar y reforzar la percepción. 
Vale la pena resaltar el papel asumido por los individuos frente a la apropiación de imágenes religiosas. Cabe destacar la preservación de la cultura popular a partir de tradiciones en que los objetos simbólicos mantienen vivos valores claves de la idiosincrasia de un grupo, ya que la imagen en sí tiene un sentido, pero al ser provista de significado por la colectividad genera nuevas formas de pensamiento y experiencias cuyo análisis permite descubrir esas otras significaciones.

En términos de expresión y sentido, la experiencia visual proviene indiscutiblemente de la actividad de la fuerza perceptual. Cualquier diseño, por sencillo que sea, cumple una función específica. En este caso, intensifica el enfoque y el impacto de la visualización del escapulario como objeto con una estructura activa.

Desde el análisis de su configuración formal, se revela en el escapulario una composición equilibrada en que la forma, la dirección y la ubicación apoyan la función de toda la estructura. Así, este elemento propio de la iconografía de la Virgen del Carmen adquiere una significación precisa acorde con el mensaje que desea transmitir y apoya la ideología de la Orden de los carmelitas.

El análisis de la construcción del escapulario como objeto evidencia una estimulación intrínseca a partir de la organización de la forma visual. La interacción genera, a su vez, una historia cultural que relaciona religión, creencia, rito y contexto, de modo que entre imagen, objeto y sujeto median construcciones simbólicas.

Existen papeles determinantes en la forma como se configuran las prácticas populares rituales que integran al ser humano con sus creencias y su quehacer diario para generar imaginarios de protección a partir de construcciones simbólicas. En este sentido, la investigación de la cultura popular permite identificar dinámicas culturales significativas para la construcción de procesos de identidad regional. 


\section{REFERENCIAS BIBLIOGRÁFICAS}

Arfuch, L. (1997). Diseño y comunicación. Teorías y enfoques críticos (Primera ed.). Buenos Aires, Argentina: Paidós.

Arnheim, R. (2010). Arte y Percepción Visual. (M. L. Balseiro, Trad.) Madrid, España: Alianza Editorial.

Blanco, M. M. (16 de marzo de 2017). La Virgen del Carmen y el escapulario del Carmen. Obtenido de María Mediadora: http://www.mariamediadora.com/Oracion/LaVirgendelCarmen-y-EscapulariodelCarmen.pdf

Canclini, N. G. (2009). Culturas Híbridas. Mexico, Mexico: Debosillo.

Catholic.net. (24 de 03 de 2017). Obtenido de www.catholic.net

Costa, J. (1971). La Imagen y el impacto psico-visual. Barcelona, España: Ediciones Zeus.

Costa, J. (1998). La esquemática. Barcelona, España: Ediciones Paidós.

Costa, J. (2003). Diseñar para los ojos (Segunda Edición ed.). La Paz, Bolivia: Grupo Editorial Design.

Donis, D. (1985). Sintaxis de la imagen. Barcelona: Gustavo Gili.

Durand, G. (1968). La imaginación Simbólica (Segunda ed.). (M. Rojzman, Trad.) Buenos Aires, Argentina: Amorrortu Editores.

Frascara, J. (2000). Diseño Gráfico y Comunicación (Séptima ed.). Buenos Aires, Argentina: Ediciones Infinito. Gruzinski, S. (2007). El pensamiento mestizo. (E. F. González, Trad.) Barcelona, España: Paidós Ibérica, S.A.

Herradón, M. A. (2001). El escapulario: Insignia de devoción mariana. Anales del museo nacional de antropología(VIII), 145 - 197.

Juez, F. M. (2002). Contribuciones para una antropologia del diseño. Barcelona, España: Gedisa S.A.

Schwimmer, E. (2006). Religión y Cultura. Barcelona: Anagrama.

Silva, A. (2000). Imaginarios urbanos. Bogotá: Editores Tercer mundo.

www.aciprensa.com. (3 de Octubre de 2014). Recuperado el 3 de Octubre de 2014, de https://www.aciprensa.com/M 